\title{
The Utilization of a New Immunochromatographic Test in Detection of Helicobacter pylori Antibody from Maternal and Umbilical Cord Serum
}

\author{
Fu-Chen Kuo, ${ }^{1,2,3}$ Chien-Yi Wu, ${ }^{4}$ Chao-Hung Kuo, ${ }^{5,6}$ Chia-Fang Wu, ${ }^{1}$ \\ Chien-Yu Lu, ${ }^{5,6}$ Yen-Hsu Chen, ${ }^{6,7}$ Chiao-Yun Chen, ${ }^{8,9}$ \\ Yi-Ching Lo, ${ }^{10}$ Ming-Tsang $\mathrm{Wu},{ }^{1}$ and Huang-Ming $\mathrm{Hu}^{5,6}$ \\ ${ }^{1}$ Graduate Institute of Public Health, Kaohsiung Medical University, Kaohsiung 807, Taiwan \\ ${ }^{2}$ Department of Gynecology and Obstetrics, E-Da Hospital, Kaohsiung 824, Taiwan \\ ${ }^{3}$ School of Medicine, College of Medicine, I-Shou University, Kaohsiung 824, Taiwan \\ ${ }^{4}$ Department of Pediatrics, E-Da Hospital, I-Shou University, Kaohsiung 824, Taiwan \\ ${ }^{5}$ Division of Gastroenterology, Department of Internal Medicine, Kaohsiung Medical University Hospital, Kaohsiung 807, Taiwan \\ ${ }^{6}$ Department of Medicine, College of Medicine, Kaohsiung Medical University, Kaohsiung 807, Taiwan \\ ${ }^{7}$ Division of Infectious Diseases, Department of Internal Medicine, Kaohsiung Medical University Hospital, Kaohsiung 807, Taiwan \\ ${ }^{8}$ Department of Radiology, College of Medicine, Kaohsiung Medical University, Kaohsiung 807, Taiwan \\ ${ }^{9}$ Department of Medical Imaging, Kaohsiung Medical University Hospital, Kaohsiung 807, Taiwan \\ ${ }^{10}$ Department of Pharmacology, College of Medicine, Kaohsiung Medical University, Kaohsiung 807, Taiwan
}

Correspondence should be addressed to Huang-Ming Hu; kevinhu837@gmail.com

Received 4 June 2014; Accepted 9 July 2014; Published 7 August 2014

Academic Editor: Seng-Kee Chuah

Copyright (c) $2014 \mathrm{Fu}$-Chen Kuo et al. This is an open access article distributed under the Creative Commons Attribution License, which permits unrestricted use, distribution, and reproduction in any medium, provided the original work is properly cited.

Background. Helicobacter pylori (H. pylori) was linked with several extragastrointestinal diseases, including preeclampsia and intrauterine growth restriction of fetus. One of the signals which can be transferred from mother to fetus is the $H$. pylori IgG antibody. Aims. We utilized a commercial immunochromatographic kit to detect the antibody in maternal and cord serum. Methods. Three hundred and forty-six females were enrolled and the blood samples were collected on antenatal examination and on delivery. The maternal $H$. pylori infection was determined by stool $H$. pylori antigen test. Results. One hundred and five females (30.3\%) were $H$. pylori-infected, and the prevalence was higher in immigrants (43.5\%) than in Taiwanese $(28.7 \%, P=0.058)$. The sensitivity, specificity, positive predictive value, negative predictive value, and accuracy of the kit were $77.1 \%, 88.0 \%, 73.6 \%, 89.8 \%$, and $84.7 \%$, respectively. This kit also had similar performance in cord serum. Comparing to the maternal result on delivery, this kit offered a consistent performance in antenatal maternal serum (kappa coefficient 0.92 ) and in cord serum (kappa coefficient 0.88 ). Conclusions. H. pylori IgG antibody can be transferred through the placenta into the fetal circulation. However, accuracy of the test kit needs to be evaluated before utilization in screening.

\section{Introduction}

Helicobacter pylori (H. pylori), a Gram-negative bacteria existing in the stomach, has been linked with many gastrointestinal diseases, such as peptic ulcer disease, gastric adenocarcinoma, and gastric mucosal-associated lymphoid tissue lymphoma [1]. Following the observation from public health studies, however, H. pylori was thought to be associated with several extragastrointestinal diseases [2], such as hematological disease (idiopathic thrombocytopenic purpura, unexplained iron deficiency anemia) [3, 4], cardiovascular disease [5], and neurological disorders [6]. Recently, studies focusing on the obstetric field mentioned the possible influence of $H$. pylori infection in pregnant female. The high prevalence of the $H$. pylori was observed in population who had preeclampsia during pregnancy [7]. The specific 
gastrointestinal symptom, hyperemesis gravidarum, was also linked with this bacterium [8], although the other study showed conflicting result [9]. These observations raise a concern about the necessity of knowing the $H$. pylori infection status for female in gestational age.

There are several methods to detect of $H$. pylori infection. One of them is the urease test using gastric mucosal tissue obtained during gastroendoscopy. Despite being proven that procedure is safe when performing on the pregnant women [10], the general unwillingness, the high cost, the invasiveness of the procedure, and the possible sampling error make it not the ideal choice for screening the $H$. pylori infection during pregnancy. The noninvasive tests include the urea breath test (UBT), the stool antigen test and the serum $H$. pylori IgG antibody test. The latest one is easy to perform during antenatal examination and the existence of the antibody was found to be associated with the intrauterine growth restriction [11]. How the maternal H. pylori antibody influences the growth of the fetus is still elusive, but, interestingly, the antibody can be transmitted transplacentally to the fetus $[12,13]$. However, the detection of the serological antibody was frustrated because of the inconsistent accuracy caused by several factors, including the different antigen extracts the kit uses and variable $H$. pylori strain in different region $[14,15]$. In the present study, we will evaluate the performance of a new immunochromatographic test kit and detect the existence of the H. pylori IgG antibody in both maternal and cord serum.

\section{Materials and Methods}

2.1. Subjects and Data Collection. This study was carried out according to the principles of the Declaration of Helsinki and was approved by the Institutional Review Board of EDa Hospital (EMRP-096-092 and EMRP-099-052). Subjects were recruited from mothers who received regular antenatal examinations and/or delivered their babies at department of Gynecology and Obstetrics of E-Da Hospital in southern Taiwan between April 2008 and September 2011. Participation was voluntary. Informed consent was obtained from each subject and personal data regarding demographic characteristics and obstetric history was collected via questionnaire after interviewing with trained interviewers on participation and/or after baby delivery. Those who have history of gastric surgery, peptic ulcer, $H$. pylori-eradication treatment, or antibiotics or proton pump inhibitor prescription within two month before delivery were excluded. Blood samples from mothers were collected on receiving antenatal examination and/or on admission for delivery. After delivery, blood samples were also collected from umbilical cord vessels representing the existence of $H$. pylori antibody in baby's circulation. The heparinized whole blood was centrifuged at 2,000 rpm for $10 \mathrm{~min}$ to isolate plasma supernatant. Stool samples from mothers were supplied during hospitalization for baby delivery. Both stool and serum samples were stored under $-20^{\circ} \mathrm{C}$ until utilized.

2.2. Serum H. pylori IgG Detection. The IgG antibody to $H$. pylori in serum was detected using a commercial immunochromatographic test kit (ASSURE H. pylori Rapid Test, MP Biomedicals, USA). The procedure followed the manufacture's protocol. In summary, $25 \mu \mathrm{L}$ defrozen serum sample were added into the square well at the lower end of the kit. When the sample front moved upstream the viewing window and reached the pink control line labeled "A," 2 drops of chase buffer were added into the oval well at upper end of the kit. Then pull the "Hp" marked tab until resistance was felt and add 1 drop of chase buffer into the square well. The result was read after 15 minutes by two trained technicians independently. Positive and negative controls were run simultaneously. The results were determined as both technicians had the same interpretation. The one which had invalid test result or discrepant interpretation was retested using a new device.

2.3. Stool H. pylori Antigen Detection. Another commercial kit (ImmunoCard STAT! HpSA, Meridian bioscience, Cincinnati, OH, USA), based on a lateral flow chromatography technique using monoclonal antibodies, was utilized for detection of $H$. pylori antigens in human stool. The procedure followed the manufacture's protocol. In summary, stool specimen (5-6 mm in diameter) was transferred into diluent vial and mixed with sample diluent. After vortexing for 15 seconds, break the tip of the vial and dispense 4 drops into the round window at the lower end of the device and read the results after 5 minutes. The results were also interpreted independently by two technicians.

2.4. Statistical Analysis. Distribution of demographic and clinical characteristics of participants by $H$. pylori status was reported as means ( \pm standard deviations $(\mathrm{SD})$ ) or number (frequency) and was analyzed by independent $t$-test, Chisquare test, and Fischer's exact test, whenever appropriate. The sensitivity, specificity, positive predictive value (PPV), and negative predictive value (NPV) of $H$. pylori status in maternal and umbilical cord serum during delivery were presented, using $H$. pylori status in maternal stool specimens as gold standard. The reliability of $H$. pylori status in maternal serum during delivery and before delivery as well as in maternal serum and umbilical cord serum during delivery was compared by Kappa coefficient. All tests were performed by SAS 9.2 statistical software (SAS Institute Inc., Cary, NC); two-sided $P$ value less than 0.05 was considered statistically significant.

\section{Results}

Total 346 pregnant women were enrolled. The demographic characteristics were listed in Tables 1 and 2. Based on the result of stool $H$. pylori antigen detection, 105 subjects were infected with $H$. pylori on baby delivery, 241 subjects had negative stool test results, and the overall infection rate was $30.3 \%$. There was no significant difference between these two groups in body mass index (BMI), education, daily habit (alcohol, smoking, and exercise), underline disease (diabetes mellitus (DM) and hypertension), and obstetric characteristics (parity, history of miscarriage, gestation age (GA), prematurity of infant, placenta weight, and gender of 
TABLE 1: Demographic and clinical characteristics of participants who were subgrouped according to $H$. pylori status determined by stool antigen test $(\mathrm{HpSA})$ on delivery $(\mathrm{N}=346)$.

\begin{tabular}{|c|c|c|c|c|c|}
\hline & & H. pylori sta & ned $b$ & & \\
\hline & & $(+)$ & & $(-)$ & $P$ value \\
\hline & $n$ & Mean \pm SD & $n$ & Mean \pm SD & \\
\hline Age (yrs) & 105 & $29.24 \pm 4.52$ & 241 & $29.15 \pm 4.49$ & 0.872 \\
\hline Height (cm) & 105 & $157.99 \pm 5.04$ & 241 & $158.88 \pm 4.92$ & 0.124 \\
\hline Prepregnant weight (kg) & 102 & $53.94 \pm 7.84$ & 237 & $55.63 \pm 9.61$ & 0.119 \\
\hline Prepregnant BMI & 102 & $21.58 \pm 2.79$ & 237 & $22.03 \pm 3.64$ & 0.209 \\
\hline Weight gain (kg) & 102 & $13.46 \pm 4.02$ & 237 & $13.02 \pm 5.07$ & 0.436 \\
\hline Placenta weight (g) & 105 & $652.09 \pm 126.10$ & 240 & $645.42 \pm 152.05$ & 0.694 \\
\hline GA (weeks) & 105 & $38.57 \pm 1.17$ & 241 & $38.45 \pm 1.42$ & 0.451 \\
\hline
\end{tabular}

SD: standard deviation.

infant). The only difference but without significance was the nationality $(P=0.058)$. Within the enrolled subjects, 39 were immigrants from Singapore (2), Thailand (2), Cambodia (3), Vietnam (14), and China (18), respectively. Seventeen (43.5\%) belonged to the $H$. pylori-infected group, and the prevalence was higher than in Taiwanese (28.7\%).

Next, we evaluated the existence of $H$. pylori IgG antibody in maternal serum. Using the immunochromatographic device to test the serum sample collected on delivery, the sensitivity, specificity, positive predictive value (PPV), negative predictive value (NPV), and accuracy were $77.1 \%, 88.0 \%$, $73.6 \%, 89.8 \%$, and $84.7 \%$, respectively (Table 3 ). This commercial test also had similar performance when testing the serum collected from umbilical vein. Within 338 umbilical serum samples (100 from babies delivered from H. pyloriinfected mothers), the sensitivity, specificity, and accuracy were $69.0 \%, 91.6 \%$, and $84.9 \%$, respectively, in comparison with maternal stool test results.

This commercial test also offers consistent results (Table 4). Within 324 participants who donated two blood samples (one collected when receiving antenatal examination and the other collected during admission for delivery), 314 had consistent result. Two participants were positive in antenatal test but negative in delivery. The situation of the other 8 cases was reversed, with negative result on antenatal but positive on delivery. The kappa coefficient was 0.92 (95\% CI 0.88-0.97). Besides, when comparing between the maternal (on delivery) and the cord serum, 89 out of $105 \mathrm{H}$. pylori-infected mothers had positive cord serum antibody detection from their babies. On the other hand, none of the baby's cord serum from $H$. pylori-negative mothers showed the existence of $H$. pylori antibody. The kappa coefficient was 0.88 (95\% CI 0.83-0.93).

\section{Discussion}

In the present study, we evaluated the $H$. pylori $\operatorname{IgG}$ antibody from maternal and cord serum using a commercial immunochromatographic test kit. It has been shown that the human immune system can produce variable antibodies with different molecular weight against $H$. pylori, either in serum (IgG) or in human milk (IgA) [13]. We found that, in cord serum, there was detectable $H$. pylori IgG antibody, and all these seropositive babies were delivered from seropositive mothers. The consistency of the H. pylori IgG antibody detection between maternal and cord serum suggested that the antibody in cord serum was transferred transplacentally, similar to the findings reported previously $[12,13]$. However, the antibody was not detected from 16 infants who were delivered from $\mathrm{H}$. pylori-seropositive mothers, and the relatively low antibody titer in cord serum might be the reason.

We utilized the stool antigen test as the gold standard of $H$. pylori infection. In fact, both UBT and stool antigen test are acceptable noninvasive test [16]. UBT has better performance, with a sensitivity of $88-95 \%$ and a specificity of $95 \%-100 \%$ [17]. It has also been proven that both 13C- (nonradioactive) and 14C-UBT (radioactive) are harmless in the pregnant female [18], with the possibility of the fetal radiation dose in the latter being much lower than the dose considered teratogenic [19]. However, the high cost and the unavailability in clinic limit its utilization. In the present study, we chose the stool antigen test for determining the $H$. pylori status and this test has been shown to have equal performance to UBT, with a sensitivity of $94 \%$ and a specificity of $92 \%$ [20].

Detection of the H. pylori IgG antibody in serum is an alternative method. The advantage of this test is that it is not affected by local changes in the stomach, such as bleeding, that could lead to false-negative results in the other tests. For female in pregnancy, it is an option to screen when they receive the regular antenatal examinations, using commercial available test kit. In the present study, we confirmed that the results obtained antenatally were consistent with the ones checked on baby delivery. However, this method has several disadvantages. Firstly, the performance of each test kit varies in different regions [21]. This depends on the H. pylori strain chosen for development of the IgG antibody and the prevalence of the strain in the given region, as the $H$. pylori strain differs in different countries or area [22]. Therefore, it is necessary to know the performance of a new test kit before utilizing it for screening. In the present study performed in southern Taiwan, the sensitivity, specificity, and accuracy of this test kit were $77.1 \%, 88.0 \%$, and $84.7 \%$, respectively, relatively lower than the data in manufacturer's instructions which was tested in the other Asian countries. Secondary, 
TABLE 2: The distribution of demographic and clinical characteristics of participants according to the $H$. pylori status determined by stool antigen test (HpSA) on delivery $(N=346)$.

\begin{tabular}{|c|c|c|c|}
\hline & \multicolumn{3}{|c|}{ H. pyloric status determined by HpSA } \\
\hline & $\begin{array}{c}\text { H. pylori }(+) \\
n(\%)\end{array}$ & $\begin{array}{c}\text { H. pylori }(-) \\
n(\%)\end{array}$ & $P$-value \\
\hline \multicolumn{4}{|l|}{ Education } \\
\hline$<$ college & $48(45.7)$ & $90(37.5)$ & \multirow{2}{*}{0.152} \\
\hline$\geqq$ college & $57(54.3)$ & $150(62.5)$ & \\
\hline \multicolumn{4}{|l|}{ Nationality } \\
\hline Taiwan & $88(83.8)$ & $218(90.8)$ & \multirow{2}{*}{0.058} \\
\hline Immigrant & $17(16.2)$ & $22(9.2)$ & \\
\hline \multicolumn{4}{|l|}{ Smoking status } \\
\hline Yes & $2(1.9)$ & $8(3.3)$ & \multirow{2}{*}{$0.729^{\mathrm{a}}$} \\
\hline No & $103(98.1)$ & $233(96.7)$ & \\
\hline \multicolumn{4}{|l|}{ Alcohol drinking } \\
\hline Yes & 0 & $2(0.8)$ & \multirow{2}{*}{$1.000^{\mathrm{a}}$} \\
\hline No & $105(100.0)$ & $238(99.2)$ & \\
\hline \multicolumn{4}{|l|}{ Exercise } \\
\hline$\geqq 1$ times/week & $37(35.2)$ & $69(28.8)$ & \multirow{2}{*}{0.229} \\
\hline$<1$ times/week & $68(64.8)$ & $171(71.3)$ & \\
\hline \multicolumn{4}{|l|}{ Diabetes mellitus } \\
\hline Yes & $4(3.8)$ & $8(3.3)$ & \multirow{2}{*}{$0.760^{\mathrm{a}}$} \\
\hline No & $101(96.2)$ & $233(96.7)$ & \\
\hline \multicolumn{4}{|l|}{ Hypertension } \\
\hline Yes & $3(2.9)$ & $17(7.1)$ & \multirow{2}{*}{0.124} \\
\hline No & $102(97.1)$ & 224 (92.9) & \\
\hline \multicolumn{4}{|l|}{ Parity } \\
\hline 1 & $51(48.6)$ & $121(50.2)$ & \multirow{3}{*}{0.806} \\
\hline 2 & $43(41.0)$ & $100(41.5)$ & \\
\hline$>3$ & $11(10.5)$ & $20(8.3)$ & \\
\hline \multicolumn{4}{|l|}{ Miscarriage } \\
\hline Yes & $13(12.4)$ & $32(13.3)$ & \multirow{2}{*}{0.820} \\
\hline No & $92(87.6)$ & 209 (86.7) & \\
\hline \multicolumn{4}{|l|}{ Type of delivery } \\
\hline NSD/VED & $72(68.6)$ & $158(65.6)$ & \multirow{2}{*}{0.585} \\
\hline $\mathrm{C} / \mathrm{S}$ & $33(31.4)$ & $83(34.4)$ & \\
\hline \multicolumn{4}{|l|}{ Prematurity } \\
\hline$<37$ weeks & $4(3.8)$ & $11(4.6)$ & \multirow{2}{*}{$1.000^{\mathrm{a}}$} \\
\hline$\geqq 37$ weeks & $101(96.2)$ & $230(95.4)$ & \\
\hline \multicolumn{4}{|l|}{ Baby gender } \\
\hline Male & $58(55.2)$ & $140(58.1)$ & \multirow{2}{*}{0.622} \\
\hline Female & $47(44.8)$ & $101(41.9)$ & \\
\hline
\end{tabular}

${ }^{\text {a }}$ Fisher's exact test.

the result cannot represent the current infection, as the antibody is still detectable months to years after successful $H$. pylori eradication $[23,24]$. So it raises a concern about the interpretation of the association between disease and $H$. pylori when the infection is determined by the existence of $H$. pylori IgG antibody. All mentioned above might be the reasons to cause fluctuated association between $H$. pylori and variable disease, including preeclampsia [25-27].
TABLE 3: The performance of the immunochromatographic test kit (ASSURE H. pylori Rapid Test) in detection of $H$. pylori IgG antibody in maternal serum collected on delivery and cord serum in comparison to the stool antigen test.

\begin{tabular}{lccccc}
\hline & Sensitivity & Specificity & PPV & NPV & Accuracy \\
& $\%$ & $\%$ & $\%$ & $\%$ & $\%$ \\
& $(n / N)$ & $(n / N)$ & $(n / N)$ & $(n / N)$ & $(n / N)$ \\
\hline Maternal & 77.1 & 88.0 & 73.6 & 89.8 & 84.7 \\
serum & $(81 / 105)$ & $(212 / 241)$ & $(81 / 110)$ & $(212 / 236)$ & $(293 / 346)$ \\
Umbilical & 69.0 & 91.6 & 77.5 & 87.6 & 84.9 \\
serum & $(69 / 100)$ & $(218 / 238)$ & $(69 / 89)$ & $(218 / 249)$ & $(287 / 338)$
\end{tabular}

$n$ : serum sample number; $N$ : stool sample number.

TABLE 4: The consistent performance of the immunochromatographic test kit (ASSURE H. pylori Rapid Test) in detection of $H$. pylori IgG antibody in cord serum and maternal serum collected antenatally and on delivery.

\begin{tabular}{|c|c|c|c|}
\hline & \multicolumn{2}{|c|}{$\begin{array}{l}\text { Maternal serum } \\
\text { on delivery }\end{array}$} & \multirow{2}{*}{$\begin{array}{c}\text { Kappa } \\
\text { coefficient } \\
(95 \% \text { CI })\end{array}$} \\
\hline & H. pylori (+) & H. pylori (-) & \\
\hline \multicolumn{4}{|l|}{$\begin{array}{l}\text { Maternal serum, } \\
\text { antenatal }\end{array}$} \\
\hline H. pylori (+) & 93 & 2 & 0.92 \\
\hline H. pylori (-) & 8 & 221 & $(0.88-0.97)$ \\
\hline \multicolumn{4}{|l|}{ Cord serum } \\
\hline H. pylori $(+)$ & 89 & 0 & 0.88 \\
\hline H. pylori $(-)$ & 16 & 233 & $(0.83-0.93)$ \\
\hline
\end{tabular}

It has been mentioned that maternal $H$. pylori infection influences the development of the fetus [11]. The mechanism of intrauterine growth restriction is still elusive. Previous study proved that transmission of infection from mother to infant was not detected on delivery [28]. Therefore, the other factors associated with this bacterium, such as the transplacentally acquired antibody, should be taken into consideration. In fact, the human immune system responding to the $H$. pylori produces variable antibodies, and most of them can be detected in cord serum [13]. Although it has been shown that the transplacentally acquired antibody does not protect infants from colonization by $H$. pylori [12], it is necessary to further investigate its possible role during pregnancy.

Following the improvement of the hygiene condition and the comprehensive utilization of eradication, the prevalence of $H$. pylori infection is decreasing in Taiwan. The overall infection rate in the present study was $30.3 \%$. Interestingly, when classifying the $H$. pylori-positive group, higher infection rate $(43.5 \%)$ was found in immigrants who came from China and south-east Asian countries where the $H$. pylori prevalence was high [29]. It is worth observing how this situation will influence the prevalence of $H$. pylori in their next generation. 


\section{Conclusion}

H. pylori is not only connected with gastrointestinal symptoms; in pregnant female, the related antibody can transfer through the placenta into the fetal circulation. The IgG antibody can be detected during antenatal examination using commercial test kit. However, accuracy of the test kit needs to be evaluated before utilization in screening. And the possible role of the $H$. pylori IgG antibody in the fetal development needs further investigation.

\section{Conflict of Interests}

The authors declare that there is no conflict of interests regarding the publication of this paper.

\section{Acknowledgments}

This study was supported by Grant from E-Da Hospital (Grant no. EDAHP99009), Kaohsiung Medical University Hospital (10104, KMUH102-2 M04), and Kaohsiung Medical University (KMU-Q103026).

\section{References}

[1] V. Conteduca, D. Sansonno, G. Lauletta, S. Russi, G. Ingravallo, and F. Dammacco, "H. pylori infection and gastric cancer: State of the art (review)," International Journal of Oncology, vol. 42, no. 1, pp. 5-18, 2013.

[2] H. Suzuki, F. Franceschi, T. Nishizawa, and A. Gasbarrini, "Extragastric manifestations of Helicobacter pylori infection," Helicobacter, vol. 16, supplement 1, pp. 65-69, 2011.

[3] K. Muhsen and D. Cohen, "Helicobacter pylori infection and iron stores: a systematic review and meta-analysis," Helicobacter, vol. 13, no. 5, pp. 323-340, 2008.

[4] D. M. Arnold, A. Bernotas, I. Nazi et al., "Platelet count response to $H$. pylori treatment in patients with immune thrombocytopenic purpura with and without $\mathrm{H}$. pylori infection: a systematic review," Haematologica, vol. 94, no. 6, pp. 850-856, 2009.

[5] G. Niccoli, F. Franceschi, N. Cosentino et al., "Coronary atherosclerotic burden in patients with infection by CagApositive strains of Helicobacter pylori," Coronary Artery Disease, vol. 21, no. 4, pp. 217-221, 2010.

[6] C. Roubaud-Baudron, P. Krolak-Salmon, I. Quadrio, F. Mégraud, and N. Salles, "Impact of chronic Helicobacter pylori infection on Alzheimer's disease: preliminary results," Neurobiology of Aging, vol. 33, no. 5, pp. 1009.e11-1009.e19, 2012.

[7] S. Cardaropoli, A. Rolfo, A. Piazzese, A. Ponzetto, and T. Todros, "Helicobacter pylori's virulence and infection persistence define pre-eclampsia complicated by fetal growth retardation," World Journal of Gastroenterology, vol. 17, no. 47, pp. 5156-5165, 2011.

[8] A. S. Cevrioglu, M. Altindis, M. Yilmazer, I. V. Fenkci, E. Ellidokuz, and S. Kose, "Efficient and non-invasive method for investigating Helicobacter pylori in gravida with hyperemesis gravidarum: Helicobacter pylori stool antigen test," Journal of Obstetrics and Gynaecology Research, vol. 30, no. 2, pp. 136-141, 2004.

[9] S. Aytac, C. Türkay, and M. Kanbay, "Helicobacter pylori stool antigen assay in hyperemesis gravidarum: a risk factor for hyperemesis gravidarum or not?" Digestive Diseases and Sciences, vol. 52, no. 10, pp. 2840-2843, 2007.

[10] S. L. Winbery and K. E. Blaho, "Dyspepsia in pregnancy," Obstetrics and Gynecology Clinics of North America, vol. 28, no. 2, pp. 333-350, 2001.

[11] G. D. Eslick, P. Yan, H. H. Xia, H. Murray, B. Spurrett, and N. J. Talley, "Foetal intrauterine growth restrictions with Helicobacter pylori infection," Alimentary Pharmacology and Therapeutics, vol. 16, no. 9, pp. 1677-1682, 2002.

[12] J. E. G. Bunn, J. E. Thomas, M. Harding, W. A. Coward, and L. T. Weaver, "Placental acquisition of maternal specific IgG and Helicobacter pylori colonization in infancy," Helicobacter, vol. 8, no. 5, pp. 568-572, 2003.

[13] M. Weyermann, C. Borowski, G. Bode et al., "Helicobacter pylori-specific immune response in maternal serum, cord blood, and human milk among mothers with and without current Helicobacter pylori infection," Pediatric Research, vol. 58, no. 5, pp. 897-902, 2005.

[14] T. T. H. Hoang, A. Rehnberg, T. Wheeldon et al., "Comparison of the performance of serological kits for Helicobacter pylori infection with European and Asian study populations," Clinical Microbiology and Infection, vol. 12, no. 11, pp. 1112-1117, 2006.

[15] W. Deankanob, C. Chomvarin, C. Hahnvajanawong et al., "Enzyme-linked immunosorbent assay for serodiagnosis of Helicobacter pylori in dyspeptic patients and volunteer blood donors," The Southeast Asian Journal of Tropical Medicine and Public Health, vol. 37, no. 5, pp. 958-965, 2006.

[16] P. Malfertheiner, F. Megraud, C. A. O'Morain et al., "Management of Helicobacter pylori infection-the Maastricht IV/Florence consensus report," Gut, vol. 61, no. 5, pp. 646-664, 2012.

[17] C. W. Howden and R. H. Hunt, "Guidelines for the management of Helicobacter pylori infection," The American Journal of Gastroenterology, vol. 93, no. 12, pp. 2330-2338, 1998.

[18] J. B. Stubbs and B. J. Marshall, "Radiation dose estimates for the carbon-14-labeled urea breath test," Journal of Nuclear Medicine, vol. 34, no. 5, pp. 821-825, 1993.

[19] Y. Bentur, D. Matsui, and G. Koren, "Safety of 14C-UBT for diagnosis of Helicobacter pylori infection in pregnancy," Canadian Family Physician, vol. 55, no. 5, pp. 479-480, 2009.

[20] D. Vaira, P. Malfertheiner, F. Megraud et al., "Diagnosis of Helicobacter pylori infection with a new non-invasive antigenbased assay. HpSA European study group," The Lancet, vol. 354, no. 9172, pp. 30-33, 1999.

[21] C. T. Loy, L. M. Irwig, P. H. Katelaris, and N. J. Talley, "Do commercial serological kits for Helicobacter pylori infection differ in accuracy? A meta-analysis," The American Journal of Gastroenterology, vol. 91, no. 6, pp. 1138-1144, 1996.

[22] M. J. Blaser, "Heterogeneity of Helicobacter pylori," European Journal of Gastroenterology and Hepatology, vol. 9, supplement 1, pp. S3-S7, 2012.

[23] K. E. L. McColl, "Helicobacter pylori infection," The New England Journal of Medicine, vol. 362, no. 17, pp. 1597-1604, 2010.

[24] J. Versalovic, "Helicobacter pylori: pathology and diagnostic strategies," The American Journal of Clinical Pathology, vol. 119, no. 3, pp. 403-412, 2003.

[25] A. Ponzetto, S. Cardaropoli, E. Piccoli et al., "Pre-eclampsia is associated with Helicobacter pylori seropositivity in Italy," Journal of Hypertension, vol. 24, no. 12, pp. 2445-2449, 2006. 
[26] E. Teran, C. Escudero, A. Calle, R. B. Ness, J. M. Roberts, and P. R. Heine, "Seroprevalence of antibodies to Chlamydia pneumoniae in women with preeclampsia," Obstetrics and Gynecology, vol. 102, no. 1, pp. 198-199, 2003.

[27] A. Conde-Agudelo, J. Villar, and M. Lindheimer, "Maternal infection and risk of preeclampsia: Systematic review and metaanalysis," The American Journal of Obstetrics and Gynecology, vol. 198, no. 1, pp. 7-22, 2008.

[28] R. Gøbel, E. L. Symonds, R. N. Butler, and C. D. Tran, "Association between Helicobacter pylori infection in mothers and birth weight," Digestive Diseases and Sciences, vol. 52, no. 11, pp. 3049-3053, 2007.

[29] N. Matsukura, S. Yamada, S. Kato et al., "Genetic differences in interleukin-1 $\beta$ polymorphisms among four Asian populations: an analysis of the Asian paradox between $H$. pylori infection and gastric cancer incidence," Journal of Experimental \& Clinical Cancer Research, vol. 22, no. 1, pp. 47-55, 2003. 


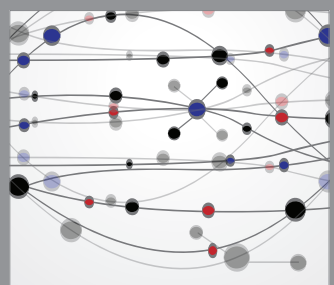

The Scientific World Journal
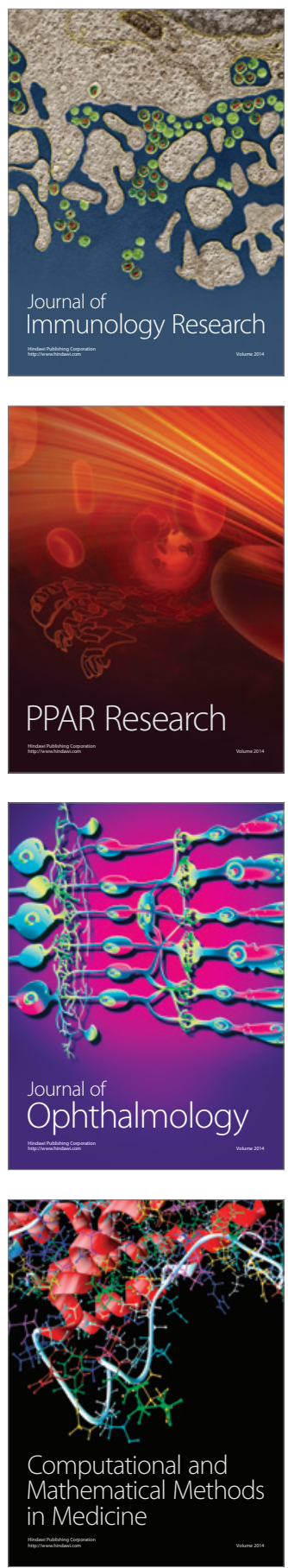

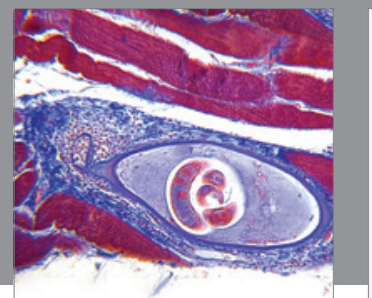

Gastroenterology

Research and Practice
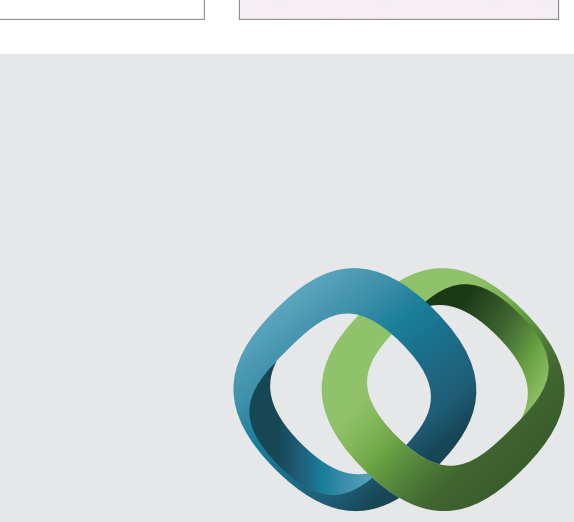

\section{Hindawi}

Submit your manuscripts at

http://www.hindawi.com
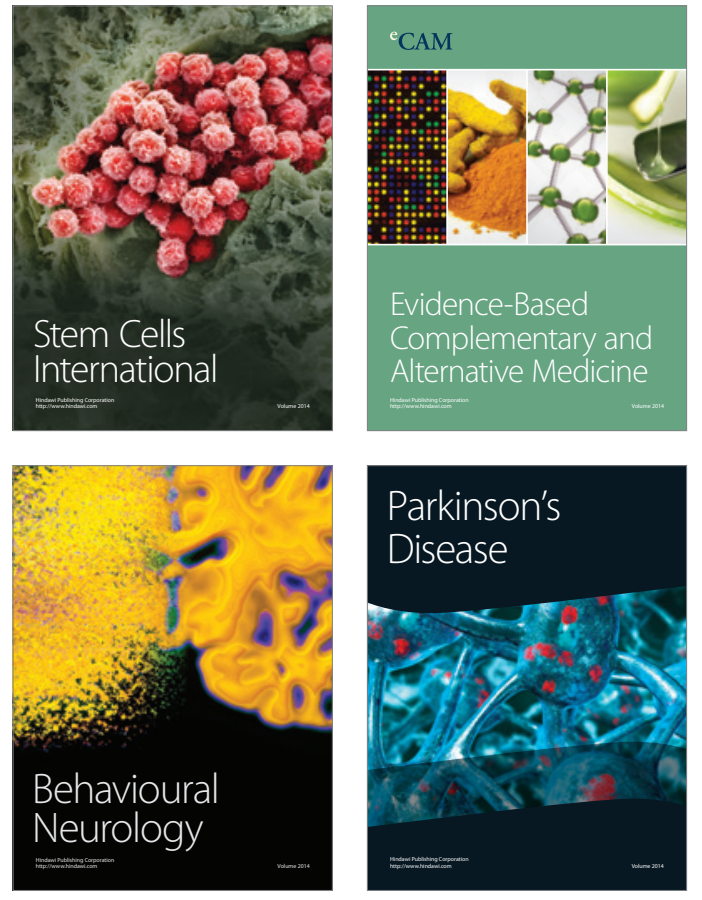
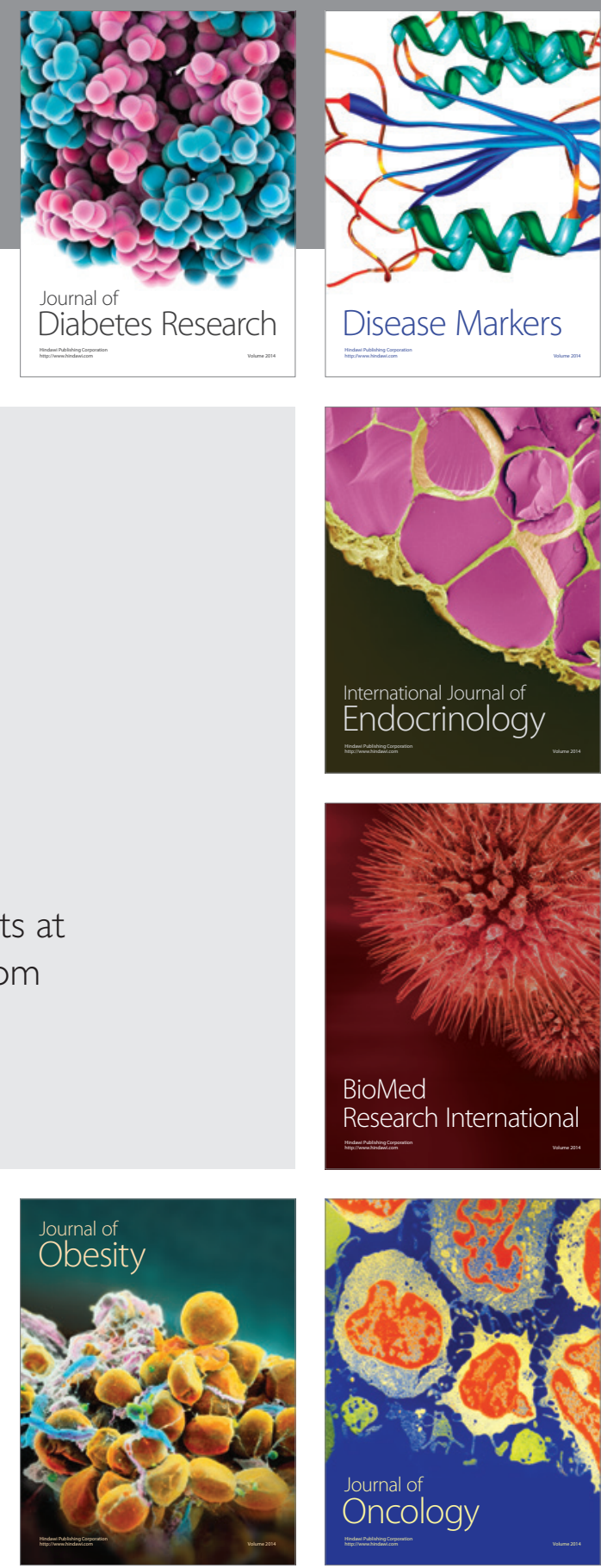

Disease Markers
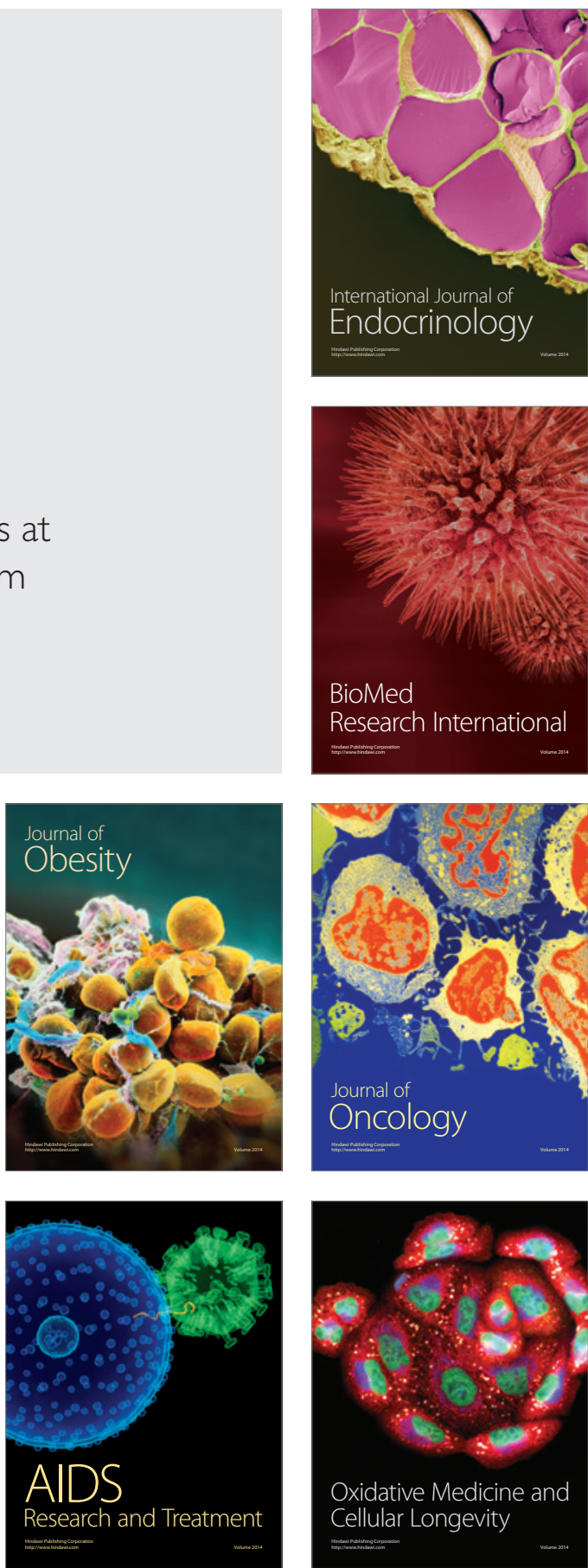